\title{
Aesculus hippocastanum Seed Fluid Extract
}

National Cancer Institute

\section{Source}

National Cancer Institute. Aesculus hippocastanum Seed Fluid Extract. NCI Thesaurus.

Code C107258.

The oil extracted from the seeds of Aesculus hippocastanum. Horse chestnut oil is used topically as a treatment for rheumatism and phlebitis. 